OPEN ACCESS

Edited by:

Daniel Saban,

Duke University, United States

Reviewed by:

Mihaela Gadjeva, Harvard Medical School,

United States

Anthony St. Leger,

University of Pittsburgh, United States

*Correspondence:

Simon Yona

s.yona@ucl.ac.uk

Anthony W. Segal

t.segal@ucl.ac.uk

tThese authors share joint first authorship

¥Present Address: Simon Yona, Faculty of Dental Medicine, Hebrew University, Jerusalem, Israel

Specialty section:

This article was submitted to Antigen Presenting Cell Biology, a section of the journal

Frontiers in Immunology

Received: 20 September 2018 Accepted: 22 January 2019

Published: 01 March 2019

Citation:

Foote JR, Patel AA, Yona S and Segal AW (2019) Variations in the Phagosomal Environment of Human Neutrophils and Mononuclear

Phagocyte Subsets.

Front. Immunol. 10:188

doi: 10.3389/fimmu.2019.00188

\section{Variations in the Phagosomal Environment of Human Neutrophils and Mononuclear Phagocyte Subsets}

\author{
Juliet R. Foote ${ }^{\dagger}$, Amit A. Patel ${ }^{\dagger}$, Simon Yona ${ }^{* \neq}$ and Anthony W. Segal ${ }^{*}$ \\ Division of Medicine, University College London, London, United Kingdom
}

The phagosome microenvironment maintains enzyme activity and function. Here we compared the phagosomal $\mathrm{pH}$ of human neutrophils, monocytes, dendritic cells (DC), and monocyte-derived cells. An unexpected observation was the striking difference in phagosomal environment between the three monocytes subsets. Classical monocytes and neutrophils exhibited alkaline phagosomes, yet non-classical monocytes had more acidic phagosomes, while intermediate monocytes had a phenotype in-between. We next investigated the differences between primary naïve DC vs. in vitro monocyte-derived $\mathrm{DC}(\mathrm{MoDC})$ and established that both these cells had acidic phagosomal environments. Across all phagocytes, alkalinization was dependent upon the activity of the NADPH oxidase activity, demonstrated by the absence of NADPH oxidase from a patient with chronic granulomatous disease (CGD) or the use of a pharmacological inhibitor, diphenylene iodonium (DPI). Interestingly, MoDC stimulated with bacterial lipopolysaccharide had increased phagosomal pH. Overall, the increase in alkalinity within the phagosome was associated with increased oxidase activity. These data highlight the heterogeneous nature and potential function of phagocytic vacuoles within the family of mononuclear phagocytes.

Keywords: neutrophil, monocyte, macrophage, dendritic cell, phagocytosis, pH, lysosome, NOX2

\section{KEY POINTS}

- Phagosomal function depends upon the action of enzymes released into them from cytoplasmic granules.

- The substantial differences in the phagosomal $\mathrm{pH}$ in the different phagocytes will affect their compliment of enzymes and their functions.

\section{INTRODUCTION}

The ability to internalize particles is an evolutionary conserved process. The downstream purpose of this process varies, from a simple feeding mechanism to a fundamental component of host defense. Within the professional phagocyte family of cells, neutrophils, macrophages, and monocyte-derived cells predominantly kill and digest microbes, whereas dendritic cells (DC) are principally involved in antigen presentation. Because all these cells are phagocytic in nature, many of their primary functions are conducted within the phagocytic vacuole, it is therefore critical to understand each cell's phagosomal microenvironment and function. 
Previous studies in neutrophils demonstrated that their phagosomal $\mathrm{pH}$ is elevated between 8.5 and 9 for at least $30 \mathrm{~min}$ following phagocytosis $(1,2)$. This alkalinization together with the influx of potassium ions (3) activates the neutral proteases released from cytoplasmic granules that kill and digest the ingested pathogen. The alkalinization in neutrophil phagosomes is accomplished by the activity of the NADPH oxidase, NOX2. Superoxide is transported by NOX2 into the phagosome where it forms products such as $\mathrm{H}_{2} \mathrm{O}_{2}$ and $\mathrm{H}_{2} 0$, consuming protons (1).

This NOX2 electron transport chain is also present in monocytes, macrophages and DC $(4,5)$. Previous studies have demonstrated that NADPH oxidase elevates the $\mathrm{pH}$ of phagosomes in monocyte-derived cells stimulated with LPS and IFN- $\gamma$ termed "M1/classically activated" (6) and has also been shown to be important for antigen processing by DC (7) although questions remain as to how this is accomplished (8).

Blood monocytes represent a versatile population of cells, composed of several subsets which differ in morphology and transcriptional profiles, described by their location in the blood (9-13). These monocyte subsets can be distinguished by the membrane expression of CD14 and CD16 in humans (13) into $\mathrm{CD}_{14}{ }^{+} \mathrm{CD}_{16}{ }^{-}$(Classical) monocytes, $\mathrm{CD} 14^{+} \mathrm{CD}^{+} 6^{+}$ (Intermediate), and $\mathrm{CD} 14^{\text {lo }} \mathrm{CD} 16^{+}$(Non-classical) monocytes (14-16). Monocytes make up around $10 \%$ of circulating white blood cells, of which classical monocytes up $\sim 85 \%$ of all monocytes, with intermediate and non-classical monocytes making up the remainder. Classical monocytes are rapidly recruited to sites of infection $(17,18)$. Non-classical monocytes have been termed patrolling monocytes as they are continuously examining endothelial cell integrity (19).

Dendritic cells bridge the gap between innate and adaptive immunity allowing the immune system to mount precise targeted responses. A key function of the DC is to sense foreign antigen in tissues and present it to $\mathrm{T}$ cells, initiating the adaptive immune response (20). DC consist of a heterogeneous family of cells that can be classified into plasmacytoid DC (pDC) or conventional $\mathrm{DC}(\mathrm{cDC})$. $\mathrm{cDC}$ can be further divided into $\mathrm{cDC} 1$ or $\mathrm{cDC} 2$ (21). cDC1 cells are known to efficiently prime $\mathrm{CD}^{+} \mathrm{T}$ cells via cross presentation $(22,23)$, while, cDC2 have a broad spectrum of activity and can polarize T cells toward Th1, Th2, and Th17 development depending on the antigen presented (24).

Phagosomal function depends upon the release of the contents of the cytoplasmic granules into the phagosome. These are largely enzymes whose optimal $\mathrm{pH}$ will vary widely, and differences in $\mathrm{pH}$ are expected to have a major influence upon cellular function.

Accordingly, we have undertaken a study to examine this parameter in the different subtypes of mononuclear phagocytes and neutrophils. In addition, we measured NADPH oxidase activity, as this in turn regulates the $\mathrm{pH}$. Major differences in these parameters in the different cell types examined were observed and are described below.

\section{MATERIALS AND METHODS}

\section{Ethics Approval}

This patient study was carried out in accordance with the recommendations of the Joint UCL/UCLH Committees on the Ethics of Human Research (Project numbers 02/0324 and $10 / \mathrm{H} 0806 / 115)$ with written informed consent from all subjects, also in accordance with the Declaration of Helsinki. The CGD patient has a mutation in the CYBB gene: c.517delC, predicting p.Leu173CysfsX16.

\section{Experimental Buffer}

Balanced salt solution (BSS) buffer contained $156 \mathrm{mM} \mathrm{NaCl}$, $3.0 \mathrm{mM} \mathrm{KCl}, 1.25 \mathrm{mM} \mathrm{KH}_{2} \mathrm{PO}_{4}, 2 \mathrm{mM} \mathrm{MgSO}, 2 \mathrm{mM} \mathrm{CaCl}_{2}$, $10 \mathrm{mM}$ glucose, $10 \mathrm{mM}$ Hepes at $\mathrm{pH}$ 7.4.

\section{Flow Cytometry Antibodies}

For neutrophil and monocyte isolation purity analysis: (from BioLegend unless otherwise stated) CD3 (FITC, HIT3a); CD19 (FITC, HIB19); CD20 (FITC, 2H7); CD56 (FITC, MEM188); CD66b (AF700, G10F5); HLA-DR (V500, G46-6, BD Biosciences); CD14 (PE, M5E2); CD16 (APC-Cy7, 3G8).

For isolation of mononuclear subsets by FACS: (from BioLegend unless otherwise stated) CD1c (PE-Cy7, L161); CD3 (FITC, HIT3a); CD11c (V450, B-ly6, BD Biosciences); CD14 (PE, M5E2); CD16 (APC-Cy7, 3G8); CD19 (FITC, HIB19); CD20 (FITC, 2H7); CD56 (FITC, MEM-188); CD66b (AF700, G10F5); CD123 (PerCP-Cy5.5, 7G3); HLA-DR (V500, G46-6 BD Biosciences).

For MoDC differentiation analysis: CD1a (BV510, BD Biosciences); CD1c (BV421, BD Biosciences); CD11c (PECy7, BioLegend); CD14 (BV711, BioLegend); CD16 (PE, BD Biosciences); CD64 (FITC, BD Biosciences); CD141 (APC, Miltenyi Biotec).

For macrophage differentiation analysis: CD80 (APC, clone 2D10); APC isotype control; CD200 receptor (PE, clone OX108); PE isotype control; CD1a (FITC) FITC isotype control (All from BioLegend).

\section{Cell Isolation and Cell Culture}

Blood was obtained in heparin vacutainers from healthy volunteers. Isolation of neutrophils: Human neutrophils from blood were isolated by dextran sedimentation followed by centrifugation through Lymphoprep ${ }^{\mathrm{TM}}$ (Axis Shield), and hypotonic lysis to remove erythrocytes. Lymphoprep ${ }^{\mathrm{TM}}$ or Ficoll ${ }^{\mathrm{TM}}$ was used as density gradient mediums, neither has been shown to have any differential effect on cell preparations (25).

Isolation of blood mononuclear cells by cell sorting: Monocytes were separated from the interphase layer of whole blood when passed through a density gradient medium (Ficoll $^{\mathrm{TM}}$, GE Healthcare), then resuspended in PBS containing $2 \%$ FCS and $2 \mathrm{mM}$ EDTA. Cells were incubated with CD3 MicroBeads (Miltenyi) to deplete CD3-postive cells using MACS Cell Separation (Miltenyi). CD3-negative enriched cells were incubated with Human Trustain FcX (BioLegend) before antibody labeling. Cell sorting was performed using FACS Aria II (BD Biosciences) as described previously (26): classical $\left(\mathrm{CD} 14^{+} \mathrm{CD} 16^{-}\right)$, intermediate $\left(\mathrm{CD} 14^{+} \mathrm{CD} 16^{+}\right)$and non-classical $\left(\mathrm{CD} 14^{\text {lo }} \mathrm{CD} 16^{+}\right)$. The $\mathrm{DC}$ isolation strategy is described in the legend of Figure 3 which uses the same antibody cocktail as monocyte subset isolation. $\mathrm{CDC} 2$ were identified 
as being HLA-DR ${ }^{+}, \mathrm{Lin}^{-}, \mathrm{CD} 14^{-} \mathrm{CD} 16^{-}, \mathrm{CD} 123^{-}, \mathrm{CD} 11 \mathrm{c}^{+}$ $\mathrm{Cd} 141^{-}$, and $\mathrm{CD} 1 \mathrm{c}^{+}$.

Generation of polarized monocyte-derived cells: monocytederived cells were polarized from monocytes, isolated as described above, by method described by Canton et al. (6), in brief: between 8 and $9 \times 10^{5}$ monocytes/well were cultured in an Ibidi $\mu$-Slide 8 well-plate (Ibidi, Germany) in RPMI 1,640 with $10 \%$ fetal bovine serum, $500 \mathrm{U} / \mathrm{ml}$ antibiotics (penicillin and streptomycin, ThermoFisher), and $10 \mathrm{mM}$ Hepes buffer (Sigma). For the generation of M1 monocyte-derived cells, the culture medium was supplemented with $60 \mathrm{ng} / \mathrm{ml}$ GM-CSF for 5 days, then for a further 2 days with $500 \mathrm{ng} / \mathrm{ml} \mathrm{LPS}$, and $60 \mathrm{ng} / \mathrm{ml} \mathrm{IFN-}$ $\gamma$. For M2 monocyte-derived cells, $60 \mathrm{ng} / \mathrm{ml} \mathrm{M}$-CSF was added for the first 5 days, then $60 \mathrm{ng} / \mathrm{ml} \mathrm{IL-} 4$ for the final 2 days.

Generation of monocyte-derived dendritic-like cells: monocytes separated from the interphase layer of whole blood on Ficoll ${ }^{\mathrm{TM}}$ were further processed with the Human monocyte enrichment kit (Easy Sep) to isolate classical monocytes. 6 $\times 10^{6}$ monocytes were cultured for 7 days in $10 \mathrm{~cm}$ dishes with $150 \mathrm{ng} / \mathrm{ml} \mathrm{GM-CSF}$ and $75 \mathrm{ng} / \mathrm{ml} \mathrm{IL-4}$ in complete RPMI medium to generate $\operatorname{MoDC}(27,28)$. For stimulation with LPS (from Salmonella abortus equi S-form (TLRgrade ${ }^{\mathrm{TM}}$ ), Enzo life sciences), after 6 days the dish medium was replaced with complete medium also containing $1 \mu \mathrm{g} / \mathrm{ml}$ LPS for another $24 \mathrm{~h}$ (29).

\section{Flow Cytometry}

All cells were resuspended in FACS buffer and incubated with Human Trustain FcX (BioLegend) on ice before antibody labeling to reduce non-specific binding. All experiments were carried on the BD LSRFortessa X20 cell analyzer.

\section{Phagosomal pH Measurements}

We have previously described the measurement of phagosomal $\mathrm{pH}$ in detail (30). Briefly, the wells of a microscopy plate ( $\mu$-Slide Angiogenesis by Ibidi) were washed twice with BSS buffer to remove non-adherent cells, then buffer containing 1 $\mu \mathrm{g} / \mu \mathrm{l}$ carboxy SNARF-1, AM ester acetate (ThermoFisher) was added for $25 \mathrm{~min}$ to label the cytosol, and then washed off with BSS buffer. The microscopy plate was mounted on a $37^{\circ} \mathrm{C}$ heated stage with or without $5 \mu \mathrm{M}$ DPI for $15 \mathrm{~min}$ for acclimatization before adding approximately $1 \times 10^{6}$ heat-killed Candida albicans (strain ATCC 10231 grown from vitroids, Sigma) labeled with SNARF-1 carboxylic acid acetate succinimidyl ester (ThermoFisher) and opsonised with human serum IgG (Vivaglobin). The cells were monitored using a $63 \times$ oil immersion on a Zeiss 700 confocal microscope. A snapshot was taken once a minute for $30 \mathrm{~min}$ when the cells were excited at $555 \mathrm{~nm}$ and the emission measured at 560-600 $\mathrm{nm}$ and $600-610 \mathrm{~nm}$.

The vacuolar $\mathrm{pH}$ was measured using a custom macro within the imaging software ImageJ (31). At least 20 cells were analyzed for each condition within one experiment, $n=3$ unless otherwise stated. The SNARF fluorescence ratio values were converted to $\mathrm{pH}$ using the standard curves as described by Levine et al. (1): the fluorescence ratios of extracellular SNARF-labeled Candida were measured in different buffer solutions $(100 \mathrm{mM} \mathrm{KCl}$ with $50 \mathrm{mM}$ buffer salt) from $\mathrm{pH} 3-13$ to construct two standard curves; the fluorescence ratios of SNARF-labeled Candida engulfed by human neutrophils were measured after the phagocytosing cells were then subjected to the same buffers with $0.3 \%$ saponin; cytoplasmic $\mathrm{pH}$ was measured in human neutrophils in the same buffers with nigericin (32).

\section{Measurement of Phagocytosis}

At the end of the kinetic phagosomal $\mathrm{pH}$ experiments, trypan blue was added to the cells to quench extracellular Candida fluorescence. $\mathrm{Z}$ stacks (8 or $91-2 \mu \mathrm{m}$ sections) were taken in two different random areas of the well for each condition in each experiment, and the total number of cells and total number of cells with at least one engulfed particle were counted using built-in microscope software (Zen, Zeiss).

\section{Amplex UltraRed Assay}

The assay was carried out as previously described (33) with 50,000 cells in each well of a 96 well-plate (Corning). In brief: $50 \mathrm{IU} / \mathrm{ml}$ of horseradish peroxidase (Sigma) and $6 \mu \mathrm{M}$ Amplex ultrared reagent (ThermoFisher) was added to the medium. A basal reading of 3 cycles was recorded before the cells were stimulated by pump injection with $3 \mu \mathrm{M}$ PMA (Sigma). The fluorescence produced by the oxidation of the Amplex by hydrogen peroxide was measured $30 \mathrm{~s}$ for $50 \mathrm{~min}$ at $590 \mathrm{~nm}$ after excitation at $540 \mathrm{~nm}$ in an Omega FluoStar plate reader (BMG Labtech) with three technical replicates for each condition.

\section{Statistics}

Unless otherwise stated, all experiments were repeated three times with three technical repeats. Each graph shows the mean with standard error. Statistical significance was calculated using one-way ANOVA analyses with Bonferroni's multiple comparison test using the GraphPad Prism version 7 (GraphPad software, La Jolla California, USA).

\section{RESULTS}

Neutrophils and monocytes have a similar ability to phagocytose pathogens in vivo (33); here we initially examined if they also have similar downstream phagosomal environments. Neutrophils and monocyte purity following isolation was confirmed by both flow cytometry and morphological examination (Figures 1A,B). Sixty-eight percentage (SEM $\pm 4.3 \%)$ of neutrophils and $48 \%( \pm 4.2 \%)$ of monocytes phagocytosed SNARF-labeled Candida. Neutrophil phagosomes were alkalinized to a $\mathrm{pH}$ of approximately 8.5 which was maintained for up to $30 \mathrm{~min}$. Similarly, the phagosomes of monocytes also became alkaline, although to a lesser degree reaching and maintaining a $\mathrm{pH}$ of $\sim 7.7$ (Figure 1C). Monocytes also had slightly lower phagocytosis index than neutrophils but was not statistically significant (Figure 1D). CGD neutrophils displayed no differences in uptake in comparison to healthy controls, while the oxidase inhibitor, diphenyleneiodonium 
A

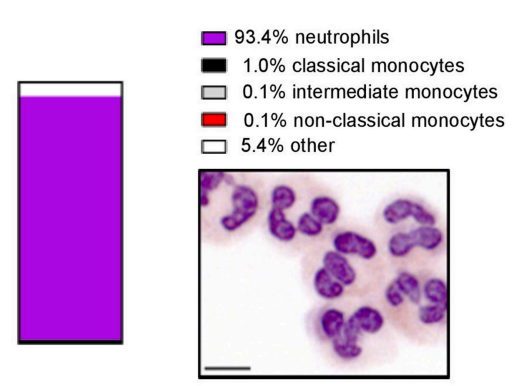

C

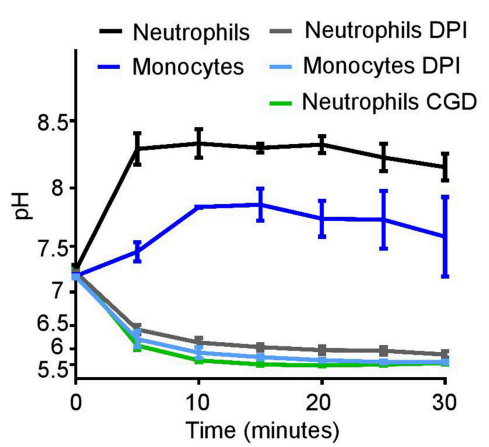

E

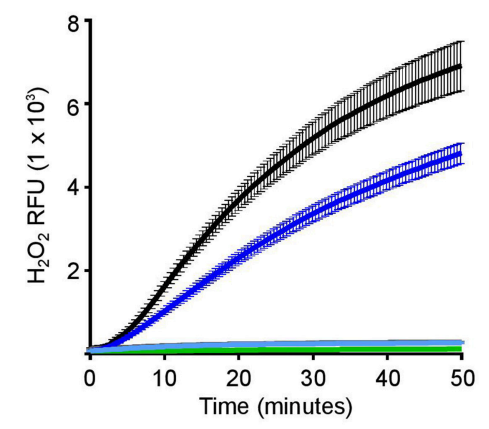

B

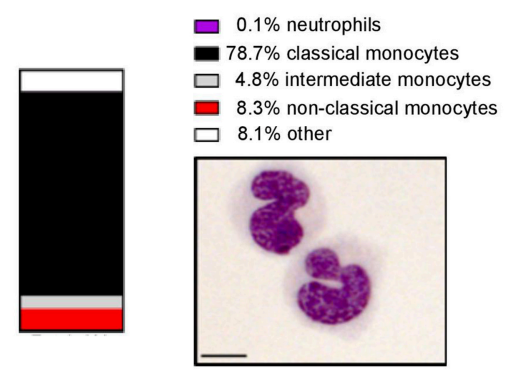

D

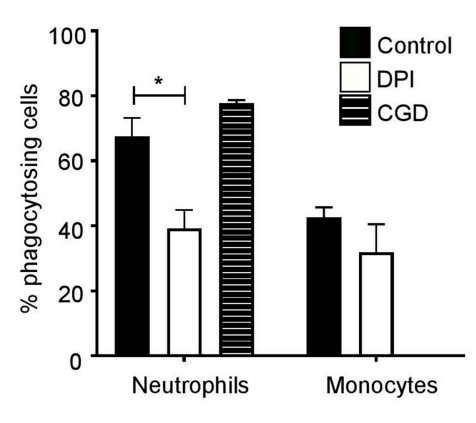

$\mathbf{F}$

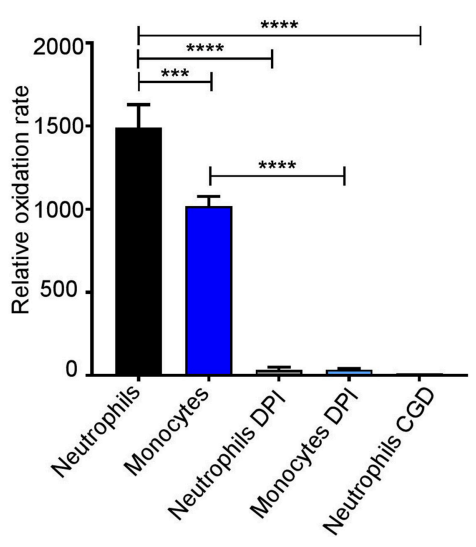

FIGURE 1 | Phagosomal pH and NOX2 activity in human neutrophils and monocytes. Isolation purity and Wright-Giemsa stained preparations of (A) neutrophils and (B) monocytes. (C) Time course of changes in phagosomal pH when cells were challenged with SNARF-labeled Candida, with (D) quantitation of the phagocytosis (mean \pm SEM). (E) Time course of changes in NADPH oxidase activity measured as hydrogen peroxide $\left(\mathrm{H}_{2} \mathrm{O}_{2}\right)$ induced relative fluorescence units (RFU) after stimulation with PMA, mean (solid lines) \pm SEM (dashed lines) and (F) maximal respiratory rate. These parameters were tested in cells from a healthy control with and without $5 \mu \mathrm{M} \mathrm{DPI}(n=3)$, an inhibitor of NOX2, and in a patient with X-linked CGD $(n=1)$. Calculated $p$-values from <one-way ANOVA with Bonferroni post-test analysis: ${ }^{\star} p<0.05,{ }^{* \star *} p<0.001,{ }^{\star \star \star \star *} p<0.0001$. The statistics for $(\mathbf{C})$ and $(\mathbf{E})$ were: $p<0.0001$ between neutrophils and DPI or CGD; monocytes and DPI; and between neutrophils and monocytes. No significance between DPI and CGD.

(DPI), decreased phagocytosis in neutrophils most likely due to off target effects.

Previous studies have demonstrated the inhibition of NOX2 activity caused phagosomal acidification (34, 35). To assess whether NOX2 regulates phagosomal $\mathrm{pH}$, cells were treated as above in the presence DPI (36). As mentioned above DPI exhibits non-specific effects, while X-linked CGD patients have a specific defect in NOX2. Here, we used cells isolated from a CGD patient to confirm the inhibition of NOX2 with DPI. Oxidase activity, measured by Amplex red oxidation was slower in monocytes as previously described $(37,38)$ (Figures 1E,F). Taken together, these data highlight a similarity of monocyte and neutrophil phagosomes. However, the question arises, is there differences in the phagosome $\mathrm{pH}$ between circulating monocyte subsets?

To address this, monocyte subsets were sorted by FACS to explore if differences in phagosomal $\mathrm{pH}$ and respiration 
A
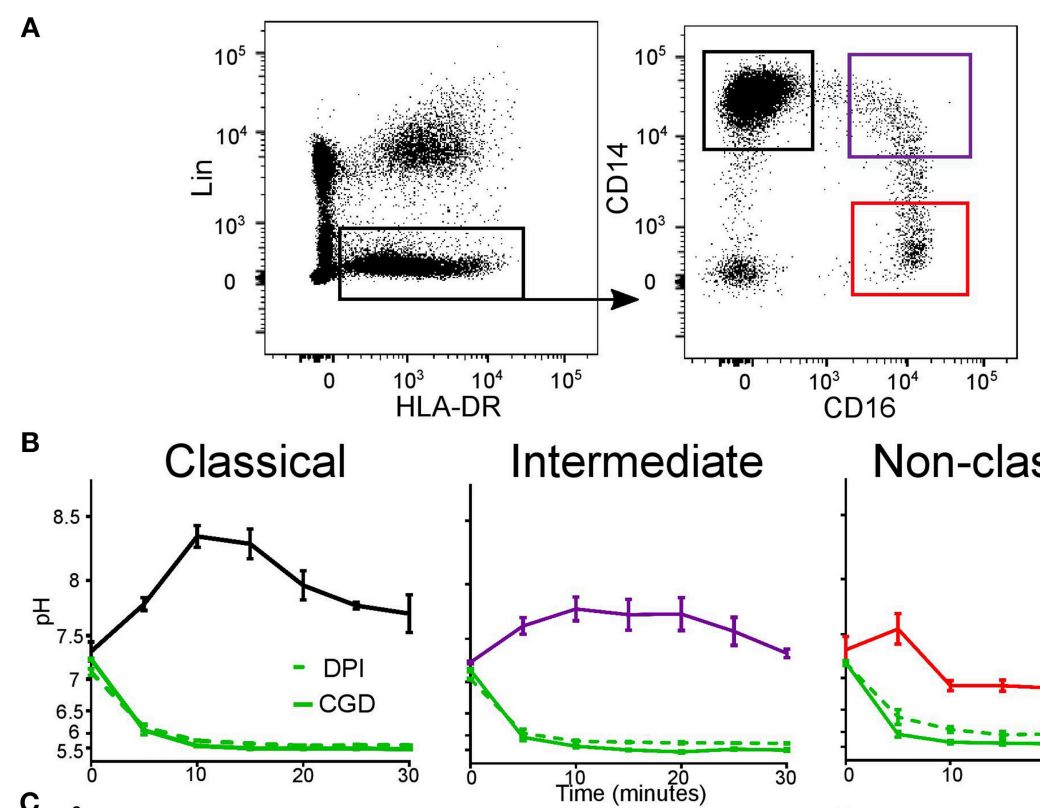

Non-classical
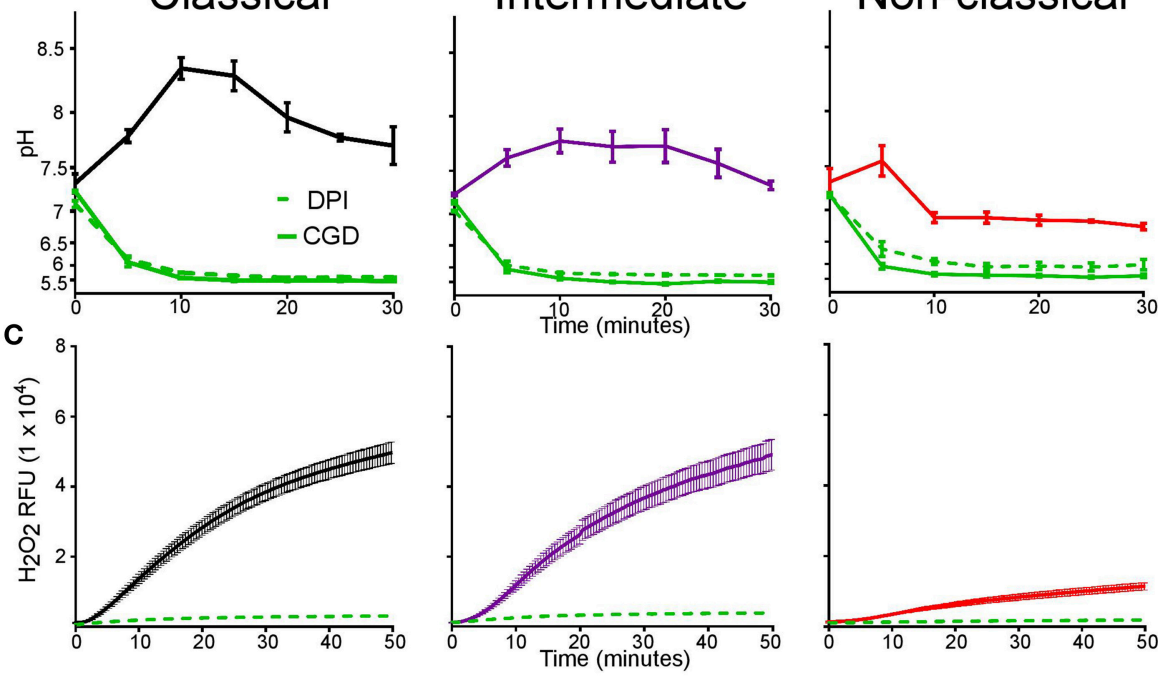

D

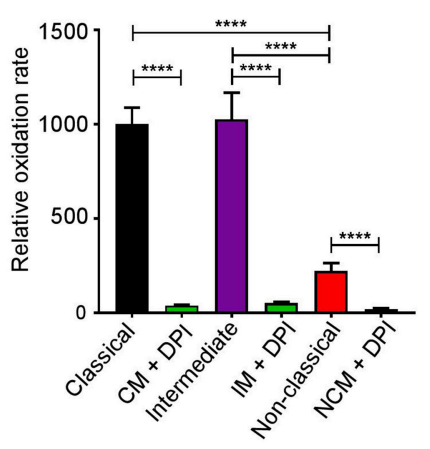

E
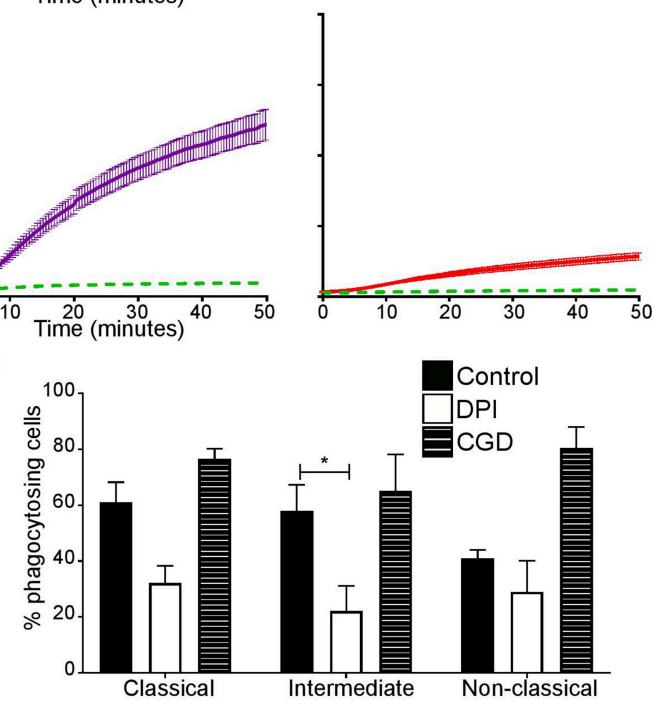

FIGURE 2 | Phagosomal pH and NOX2 activity differed between monocyte subsets. (A) FACS isolation gating strategy of the three monocyte subsets based on CD14 and CD16 expression (shown in colored boxes). Lineage cells which expressed CD1C, CD3, CD11C, CD19, CD20, CD56, CD66b, or CD123 were excluded. (B) Time course of changes in phagosomal pH in monocyte subsets over the first 30 min after phagocytosis. The effects of $5 \mu \mathrm{M}$ DPI $(n=3$, dashed green line) and measurements from an X-linked CGD patient cells ( $n=1$, solid green line) are also shown. (C) Respiratory burst activity in subsets in response to stimulation with PMA, mean (solid line) \pm SEM (dashed line). (D) Compiled results of the maximum rates from (C) mean \pm SEM. (E) Quantitation of phagocytosis from experiments in (B), mean \pm SEM. Calculated $p$-values from one-way ANOVA with Bonferroni post-test analysis: ${ }^{\star} p<0.05,{ }^{* \star \star \star} p<0.0001$. The statistics for phagosomal $p H$ (B) between monocyte control conditions for each subset for pH was $p<0.001$, and also for control vs. DPI and CGD. No statistical significance was found between DPI and CGD for all subsets. For the respiratory burst (C), no significance was found between classical and intermediate controls, but $p<0.001$ for classical and intermediate controls vs. DPI, and $p<0.01$ for non-classical control vs. DPI.

exist (Figure 2A). Interestingly, the phagosomal $\mathrm{pH}$ in all three subsets were distinct (Figure 2B). The phagosomes of classical monocytes alkalinised to around $\mathrm{pH} 8.5$ by $10 \mathrm{~min}$, after which the $\mathrm{pH}$ gradually fell to around 7.7. While, non-classical monocytes showed a brief alkalinization at about $5 \mathrm{~min}$ after which the $\mathrm{pH}$ fell to below 7.0 and remained slightly acidic. The $\mathrm{pH}$ of intermediate monocyte phagosomes was in-between that of the other two subsets.

As in neutrophils, the alkalinization of the phagosomes was produced through the action of NOX2 since the vacuolar 
$\mathrm{pH}$ of all monocyte subsets was acidic obtained from CGD cells or following treatment with DPI (Figure 2C). The rate of the respiratory burst was similar for the classical and intermediate monocytes while slower in non-classical monocytes. In all subsets, respiration was significantly inhibited by DPI (Figure 2D). On the other hand, phagocytic capacity remained equal (around 50\%) (Figure 2E), DPI only affected phagocytosis in intermediate monocytes.

At least three subsets of DCs can found in human peripheral blood (39, 40), plasmacytoid DCs (pDC), cDC1 $\left(\mathrm{CD} 141^{+}\right)$, and $\mathrm{cDC} 2\left(\mathrm{CD}_{1} \mathrm{c}^{+}\right)$(Figure 3A). Upon examination of $\mathrm{DC}$ phagosomes we were unable to detect phagocytosis of the

A

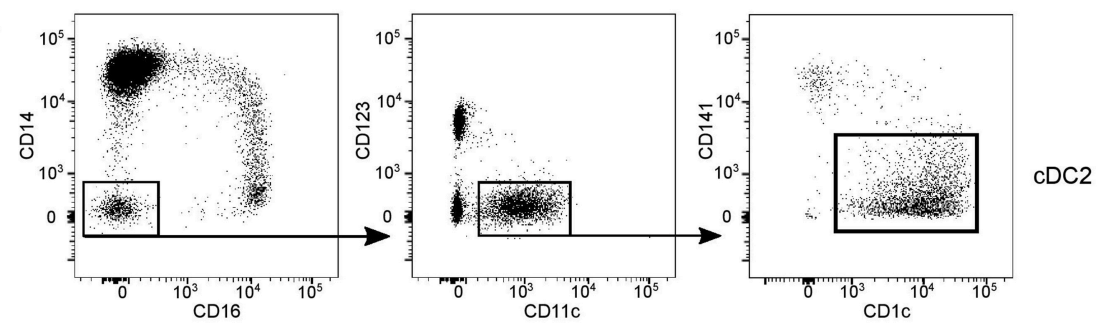

B

Classical monocytes vs. MoDCs

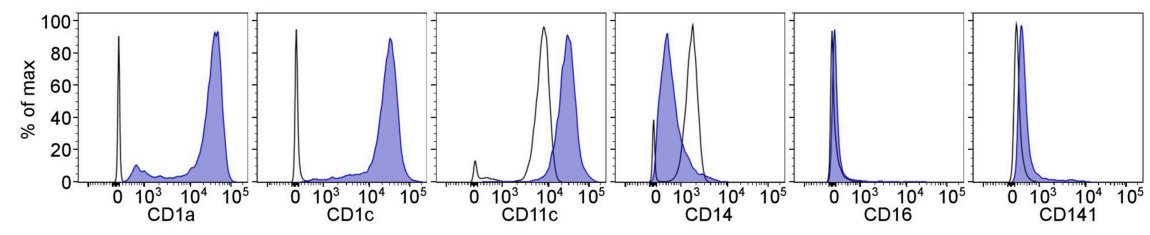

C

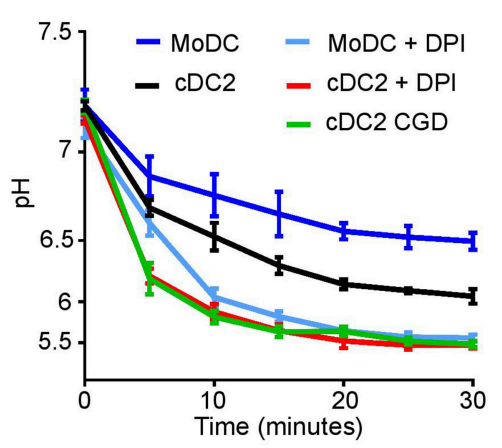

D

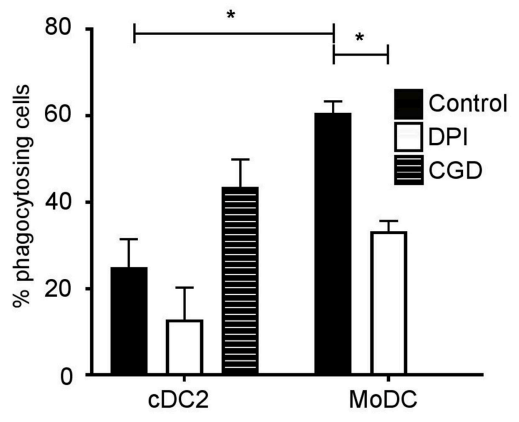

E

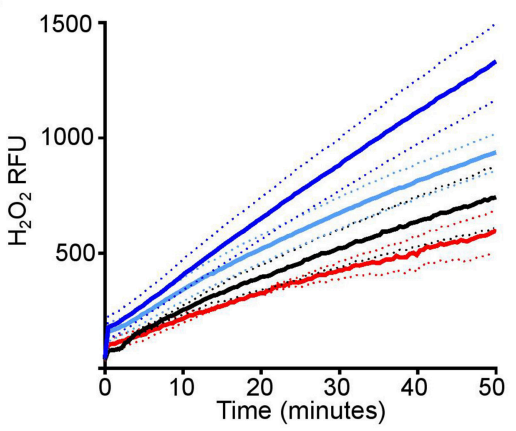

$\mathbf{F}$

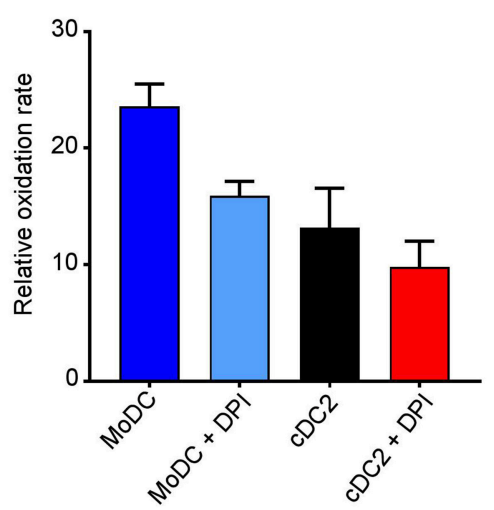

FIGURE 3 | Comparison of CDC2 and monocyte-derived DCs. (A) Gating strategy used to isolate CDC2 (CD1C ${ }^{+}$DCs) using FACS; (B) in vitro derived-MoDC were phenotypically validated according to surface markers by comparison with their precursor classical monocytes $(40,41)$, a representative plot is shown based on three experiments; (C) Time course of changes in the $\mathrm{pH}$ in the phagosomes of MoDC and $\mathrm{CDC} 2$ mean \pm SEM, from a healthy subject, with and without DPI ( $n=3$ ), and cDC2 from a CGD patient $(n=1)$; (D) quantitation of phagocytosis from (C), mean \pm SEM. (E) NADPH oxidase activity in response to PMA stimulation in MoDs and $\mathrm{CDC} 2$ in the presence and absence of $5 \mu \mathrm{M} \mathrm{DPI}$, mean (solid line) $\pm \mathrm{SEM}$ (dashed line); (F) maximal rates of respiration from (E), mean $\pm \mathrm{SEM}$. Calculated $p$-values from one-way ANOVA with Bonferroni post-test analysis: ${ }^{*} p<0.05$. For statistics of phagosomal $\mathrm{pH}$ (C) $p<0.05$ for $\mathrm{cDC} 2 \mathrm{vs}$. MoDC; $p<0.001$ for $\mathrm{cDC} 2 \mathrm{vs}$. DPI and for $\mathrm{CDC} 2$ vs. CGD; $p<0.001$ for MoDC vs. DPI. For the respiratory burst (E): $p<0.01$ for CDC2 vs. MoDC; no significance was found between cDC2 and cells with DPI, but $p<0.001$ for MoDC vs. DPI. 
SNARF-labeled Candida in the pDC fraction, and could not obtain sufficient $\mathrm{CDC} 1$ for their adequate examination. Therefore, the $\mathrm{CDC} 2$ population was examined and compared with in vitro monocyte-derived DC (Figure 3B), which are believed to mimic monocyte-derived cells that differentiate into dendritic-like cells when entering inflamed tissues. It was important to compare primary $\mathrm{CDC}$ with in vitro monocytederived DC as these cells have been an invaluable tool to many research groups in lieu of primary $\mathrm{CDC}$ (due to their relative scarcity). Yet, it is important to note, the ontogeny $(42,43)$ and transcriptome (44) are distinct between naturally occurring cDC and monocyte-derived DC.

We found that the phagosomal $\mathrm{pH}$ was slightly less acidic in MoDC compared with primary circulating CDC2 (Figure 3C).
Upon the addition of DPI, the $\mathrm{pH}$ decreased further $(p<0.001$ in both $\mathrm{CDC} 2$ and MODC types), resembling levels observed in cDC2 from the CGD patient. Interestingly, $\mathrm{cDC} 2$ were much less phagocytic than MoDC, with a mean percentage of $23.4 \pm 4.6$ SEM in comparison with $60.0 \pm 3.1$, respectively, which may correspond with previous findings that MoDC are superior at receptor mediated endocytosis of immune complexes (28).

The amount and rate of hydrogen peroxide production in response to PMA was lower in both $\mathrm{CDC} 2$ and MoDC (Figures 3E,F) in comparison to neutrophils and monocytes (Figures 1E,F). MoDC produced significantly more $\mathrm{H}_{2} \mathrm{O}_{2}$ than $\mathrm{cDC} 2(p<0.01)$, which was further lowered by DPI $(p<0.001)$, however was not significant in $\mathrm{CDC} 2$.

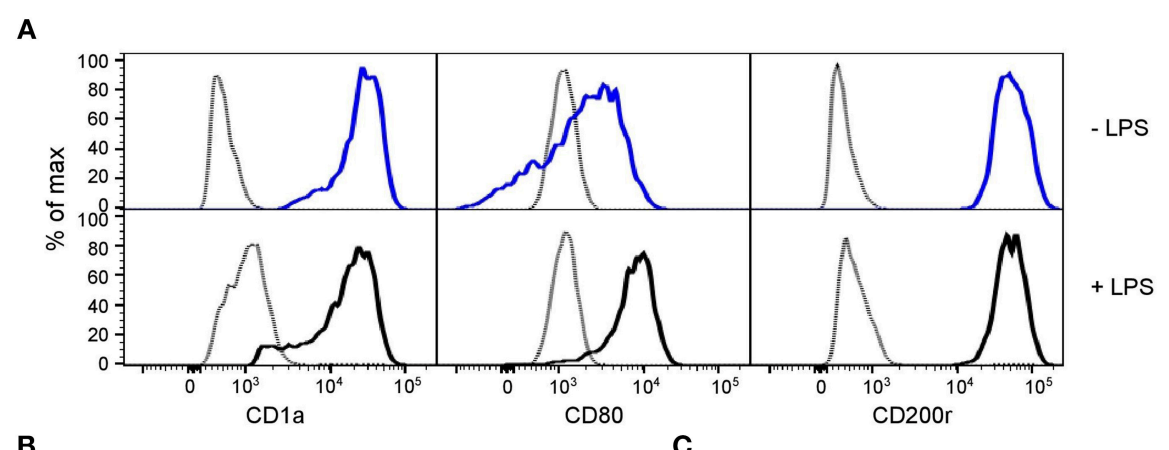

B
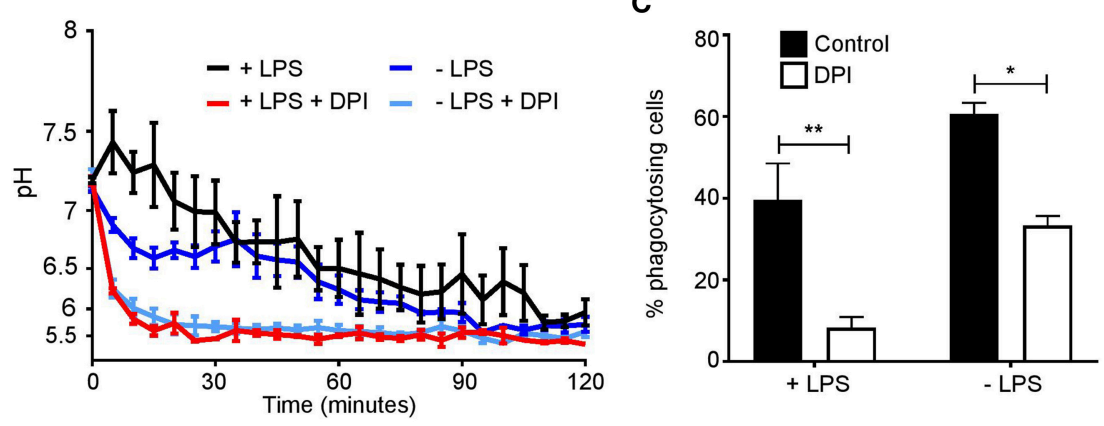

D

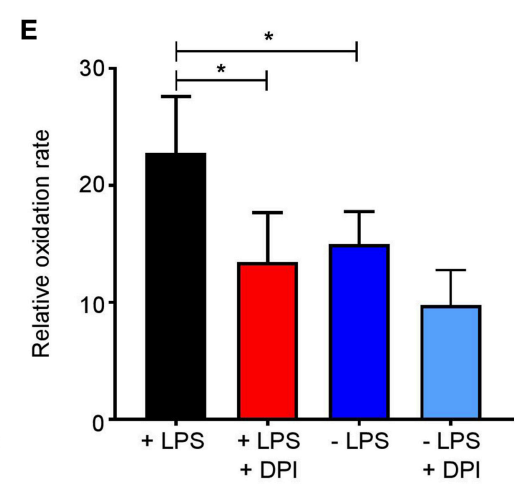

FIGURE 4 | MoDC stimulated with LPS have more alkaline phagosomes and greater NADPH oxidase activity than untreated MoDC. (A) Flow cytometry phenotypic analysis of differentiation in untreated and LPS-treated MoDC. Gray, unstained controls; dark blue, untreated MoDC; black line, LPS + MoDC. (B) Time course of changes in phagosomal $\mathrm{pH}$ over $2 \mathrm{~h}$ in cells with and without $5 \mu \mathrm{M}$ DPI, mean \pm SEM. (C) Quantitation of phagocytosis from (B), mean \pm SEM. (D) Time course of changes in NADPH oxidase activity in response to PMA stimulation, mean (solid line) \pm SEM (dashed line); (E) relative oxidation rate calculated from the final 30 min of (D). Calculated $p$-values from one-way ANOVA with Bonferroni post-test analysis: ${ }^{\star \star} p<0.01,{ }^{\star} p<0.05, n=3$. Statistics for (B) and (D) $p<0.0001$ between control untreated and LPS-treated MoDC, and $p<0.0001$ between control and DPI-treated cells. 

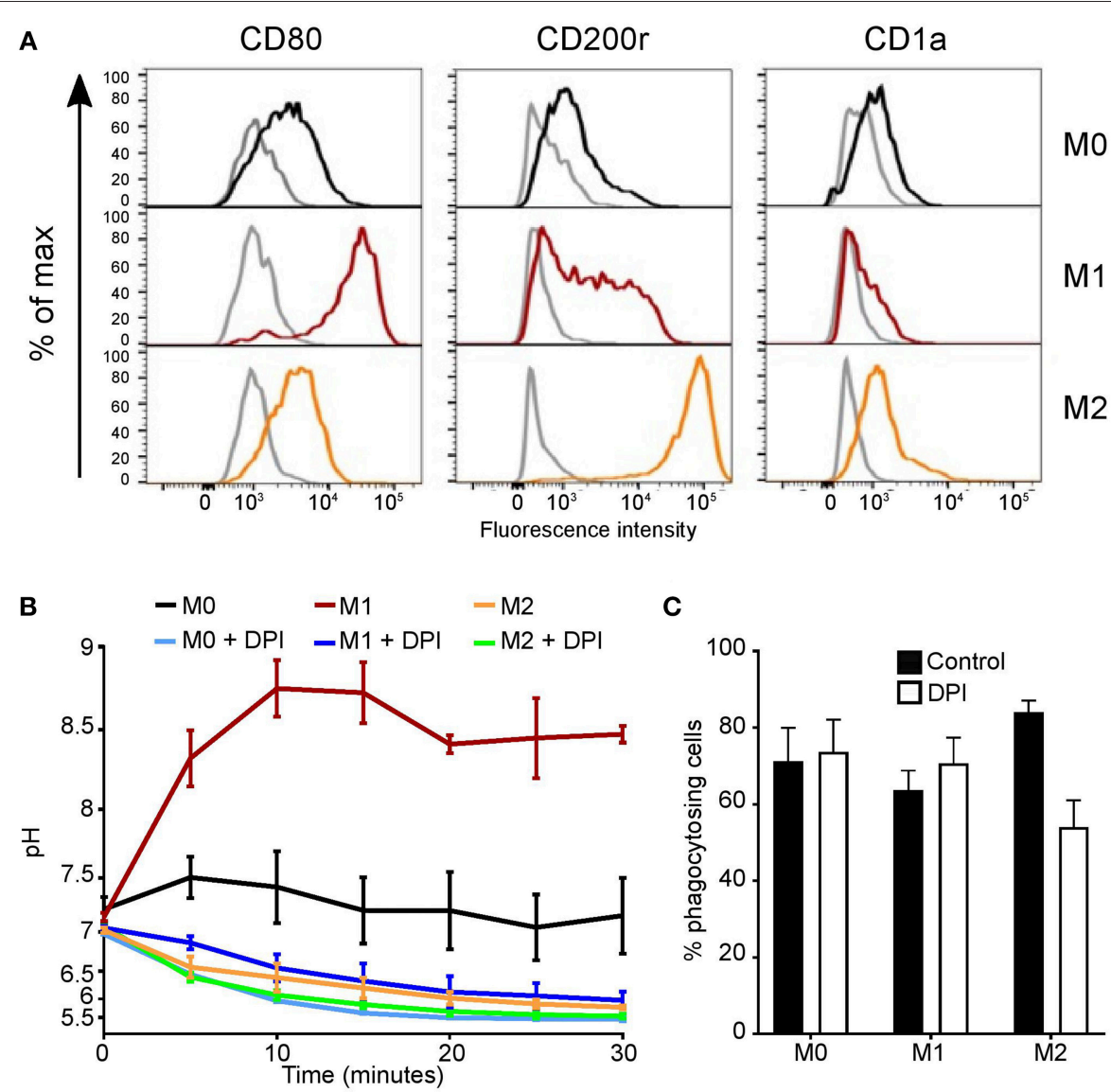

FIGURE 5 | Polarized monocyte-derived cells have different phagosomal pH profiles. (A) Phenotypic validation by flow cytometry of monocyte-derived cells differentiation from undifferentiated "M0" cells into classically activated "M1" and alternatively activated "M2" monocyte-derived cells. CD80 was used as a marker for M1 differentiation, CD200r for M2, and CD1a to exclude dendritic cells differentiation. Isotype controls are shown in gray, representative of $n=3$. (B) Time course of phagosomal $\mathrm{pH}$ in the three monocyte-derived cell populations with and without $5 \mu \mathrm{M}$ DPI, mean $\pm \mathrm{SEM}, n=3$. (C) Quantitation of phagocytosis from (B), mean \pm SEM, $n=3$. Calculated $p$-values from one-way ANOVA with Bonferroni post-test analysis: for phagosomal $\mathrm{pH}$ (B) $p<0.001$ for between all controls, $p<0.001$ for M1 vs. M1 DPI and M0 vs. M0 DPI, ns for M2 vs. M2 DPI.

Differences between our data and others who reported the phagosomal $\mathrm{pH}$ to be alkaline could be accounted for by LPS treatment. We were able to alter the activity of MoDC with $1 \mu \mathrm{g} / \mathrm{ml} \mathrm{LPS}$ for $24 \mathrm{~h}(27,29,45)$. Phenotypic changes were first investigated looking at CD1a, CD80, and CD200r expression (Figure 4A). Both untreated and LPS-treated cells had a high expression of CD1a and CD200r, while LPS-treated MoDC had increased expression of CD80 in comparison to untreated cells. Measurements of the functional assays were increased to $2 \mathrm{~h}$ in line with other studies $(7,46,47)$. Within the first $30 \mathrm{~min}$, LPS-treated MoDC had a more alkaline phagosomal $\mathrm{pH}$ than untreated MoDC peaking at $\mathrm{pH} 7.45$ at $5 \mathrm{~min}$, after which both cell conditions further acidified to $\mathrm{pH} 5.5$ (Figure 4B). DPI caused immediate acidification in both cell types. Fewer LPS-treated MoDC phagocytosed opsonized Candida than nontreated MoDC, but not by a significant margin. Interestingly, DPI adversely affected phagocytosis in both cell types (Figure 4C).

Initially, no marked difference was observed in respiratory burst between treated and untreated cells within the first $50 \mathrm{~min}$
(Figure 4D), at $2 \mathrm{~h}$ treated $\mathrm{MoDC}$ produced a higher $\mathrm{H}_{2} \mathrm{O}_{2}$ induced fluorescence than untreated MoDC $(p<0.0001)$. LPStreated cells maintained a linear rate over the recorded $2 \mathrm{~h}$, while in untreated cells the rate started to decline from 30 min onwards. The relative oxidation rate (Figure 4E) was calculated over the last $30 \mathrm{~min}$ of the time course to highlight this difference. The measured increase at this endpoint between naïve and LPStreated MoDC was $\sim 22 \%$.

Finally, we measured the phagosomal $\mathrm{pH}$ of "M1/classically activated" and "M2/alternatively activated" monocytederived cells and undifferentiated state "M0" cells. We first confirmed that the identity of these in-vitro polarized cells (Figure 5A). The phagosomal pH of "M1" monocytederived cells, were alkaline at $5 \mathrm{~min}$ following phagocytosis, similar to neutrophils, and maintained a phagosomal $\mathrm{pH}$ of $\sim 8.5$ (Figure 5B). In contrast, "M2" monocyte-derived cells acidified their phagosomes in a similar fashion to non-classical monocytes. "M0" cells reached a $\mathrm{pH}$ between that of "M1" and "M2" monocyte-derived cells, this was 
due to both acidic and alkaline phagosomes. There was no significant change in $\mathrm{pH}$ between "M2" cells with and without DPI, suggesting this is independent of NOX2-these data corroborate previous elegant studies conducted by Canton et al. (6). There were no significant differences in phagocytosis index between these cells with and without DPI (Figure 5C).

\section{DISCUSSION}

The phagosome in professional phagocytes falls into two main categories, pathogen killing and digestion, or antigen processing, and presentation. Both these roles require the activity of digestive enzymes and these in turn are highly dependent upon the conditions within the phagocytic vacuole.

It is known that the neutrophil and monocyte cytoplasmic granules contain a variety of enzymes, including lysozyme, and myeloperoxidase (48-50), although more poorly classified in monocytes. The $\mathrm{pH}$ optima varies between such enzymes for example myeloperoxidase tested in neutrophils is $\mathrm{pH}$ 5-6 (1) whereas, lysozyme (tested in serum) lies between pH 8-9 (51). Our observation of differences in phagosomal $\mathrm{pH}$ between monocyte subsets, may indicate that (a) these enzymes are present in different subsets of monocytes, (b) they are contained within different granules which degranulate at different times in the evolution of the vacuole, or (c) that the timing of their activity varies with temporal changes in the vacuole.

Our results highlight that, like neutrophils, classical monocytes develop alkaline vacuoles. In addition, the duration and extent of vacuolar alkalinization varies considerably between monocyte subsets, suggesting functional diversity between the cells.

The results on polarized monocyte-derived cells mirrored those described by Grinstein (6), in addition we also observed non-polarized "M0" monocyte-derived cells were more acidic than the "M1" cells yet distinct from the "M2" monocytederived cells. The phagosomal $\mathrm{pH}$ of "M1" and "M0" cells were acidified significantly with the addition of DPI, whereas this was not true for "M2" monocyte-derived cells. It is apparent that the mechanism regulating phagosomal $\mathrm{pH}$ differs between monocyte-derived cells states, either dependent or independent of NOX2, consequently warranting further investigation.

The role of the NADPH oxidase and antigen handling by dendritic cells remains a point of contention. A number of groups report that mouse bone marrow-derived DC $(46,52)$ and human blood DC (53) have an alkaline phagosomal $\mathrm{pH}$ ( $\mathrm{pH} 7-8$ ), elevated by the NADPH oxidase, which is necessary for optimal antigen processing and presentation. On the other hand, Rybicka et al. (8) reported that mouse BMDC and splenic DCs had acidic phagosomal pHs that were unaltered by the activity of the oxidase, and proposed that it was the reducing environment, indirectly linked to the $\mathrm{pH}$, rather than the proton concentration that was important for antigen presentation. Similarly, others have observed comparable results also using mouse BMDC (54). In human MoDC several groups have reported an acidic phagosomal $\mathrm{pH}$ following phagocytosis $(47,55)$.

In accordance with these findings, we did not observe the vacuolar $\mathrm{pH}$ of either naïve $\mathrm{CDC} 2$ or the majority of MoDC to become alkaline during our analysis. However, when we stimulated the cells with LPS, the phagosomes of many MoDC became alkaline. Additionally, the NADPH oxidase activity was higher in these cells than untreated MoDC. This observation is in line with studies by Savina et al. (56), who demonstrated $\mathrm{NADPH}$ oxidase influences the vacuolar $\mathrm{pH}$, further supported in both MoDC and $\mathrm{CDC} 2$ when the oxidase was absent in CGD or inhibited by DPI, but further work is required to help understand the relationship between phagosomal $\mathrm{pH}$ and DC function.

There is also the possibility that different pathogens alter the phagosome, for instance, Mycobacterium infection in macrophages change the phagosomal $\mathrm{pH}$ by interfering with the onset of acidification $(57,58)$. In this study, we utilized dead yeast organisms as a tool to assess phagosomal $\mathrm{pH}$, as live organisms do not efficiently retain SNARF-1. We hope that further technical advances will help elucidate the effect of live organisms on the phagosome.

Here, we demonstrate differences in the vacuole environments between neutrophils, monocytes, dendritic cells, and monocyte-derived cells. This will consequently have downstream effects on the enzymology within these compartments. To further explore tissue macrophage heterogeneity, primary macrophages from distinct tissue i.e., lung alveolar macrophages or skin Langerhans cells could be examined. Future work identifying enzymes released into the vacuoles, will enable a better understanding of the function of these cells.

\section{AUTHOR CONTRIBUTIONS}

JF and AP isolated and cultured cells and performed flow cytometry experiments. AP performed purity analyses. JF performed and analyzed microscopy experiments and Amplex UltraRed assays and made the figures. SY and AS designed the research, all authors wrote the paper.

\section{FUNDING}

JF was supported by an Irwin Joffe Memorial Fellowship. AP was supported by an EPSRC studentship.

\section{ACKNOWLEDGMENTS}

We thank Siobhan Burns and Fernando Moreira for their clinical assistance, Dirk Roos for sequencing data of the CGD patient, Jamie Evans for flow cytometry assistance. Finally, we thank all the volunteers and patients for donating their blood. 


\section{REFERENCES}

1. Levine AP, Duchen MR, de Villiers S, Rich PR, Segal AW. Alkalinity of neutrophil phagocytic vacuoles is modulated by HVCN1 and has consequences for myeloperoxidase activity. PLoS ONE. (2015) 10:e0125906. doi: 10.1371/journal.pone.0125906

2. Segal AW, Geisow M, Garcia R, Harper A, Miller R. The respiratory burst of phagocytic cells is associated with a rise in vacuolar pH. Nature. (1981) 290:406-9. doi: 10.1038/290406a0

3. Reeves EP, Lu H, Jacobs HL, Messina CG, Bolsover S, Gabella G, et al. Killing activity of neutrophils is mediated through activation of proteases by $\mathrm{K}^{+}$flux. Nature. (2002) 416:291-7. doi: 10.1038/416291a

4. Segal AW, Garcia R, Goldstone H, Cross AR, Jones OT. Cytochrome b245 of neutrophils is also present in human monocytes, macrophages and eosinophils. Biochem J. (1981) 196:363-7. doi: 10.1042/bj1960363

5. Elsen S, Doussière J, Villiers CL, Faure M, Berthier R, Papaioannou A, et al. Cryptic O2- -generating NADPH oxidase in dendritic cells. J Cell Sci. (2004) 117:2215-26. doi: 10.1242/jcs. 01085

6. Canton J, Khezri R, Glogauer M, Grinstein S. Contrasting phagosome $\mathrm{pH}$ regulation and maturation in human M1 and M2 macrophages. Mol Biol Cell. (2014) 25:3330-41. doi: 10.1091/mbc.e14-05-0967

7. Mantegazza AR, Savina A, Vermeulen M, Pérez L, Geffner J, Hermine $\mathrm{O}$, et al. NADPH oxidase controls phagosomal $\mathrm{pH}$ and antigen crosspresentation in human dendritic cells. Blood. (2008) 112:4712-22. doi: 10.1182/blood-2008-01-134791

8. Rybicka JM, Balce DR, Chaudhuri S, Allan ER, Yates RM. Phagosomal proteolysis in dendritic cells is modulated by NADPH oxidase in a pH-independent manner. EMBO J. (2012) 31:932-44. doi: 10.1038/emboj.2011.440

9. Geissmann F, Jung S, Littman DR. Blood monocytes consist of two principal subsets with distinct migratory properties. Immunity. (2003) 19:71-82. doi: 10.1016/S1074-7613(03)00174-2

10. Ingersoll MA, Spanbroek R, Lottaz C, Gautier EL, Frankenberger M, Hoffmann $\mathrm{R}$, et al. Comparison of gene expression profiles between human and mouse monocyte subsets. Blood. (2010) 115:e10-9. doi: 10.1182/blood-2009-07-235028

11. Yona S, Jung S. Monocytes: Subsets, origins, fates and functions. Curr Opin Hematol. (2010) 17:53-9. doi: 10.1097/MOH.0b013e3283324f80

12. Mildner A, Schönheit J, Giladi A, David E, Lara-Astiaso D, Lorenzo-Vivas E, et al. Genomic characterization of murine monocytes reveals C/EBP $\beta$ transcription factor dependence of Ly6C-cells. Immunity. (2017) 46:84962.e7. doi: 10.1016/j.immuni.2017.04.018

13. Guilliams M, Mildner A, Yona S. Developmental and functional heterogeneity of monocytes. Immunity. (2018) 49:595-613. doi: 10.1016/j.immuni.2018.10.005

14. Ziegler-Heitbrock L, Ancuta P, Crowe S, Dalod M, Grau V, Hart DN, et al. Nomenclature of monocytes and dendritic cells in blood. Blood (2010) 116:e74-80. doi: 10.1182/blood-2010-02-258558

15. Wong KL, Tai JJ, Wong WC, Han H, Sem X, Yeap WH, et al. Gene expression profiling reveals the defining features of the classical, intermediate, and nonclassical human monocyte subsets. Blood. (2011) 118:e16-31. doi: 10.1182/blood-2010-12-326355

16. Passlick B, Flieger D, Ziegler-Heitbrock H. Identification and characterization of a novel monocyte subpopulation in human peripheral blood. Blood. (1989) 74: $2527-34$.

17. Liao CT, Andrews R, Wallace LE, Khan MW, Kift-Morgan A, Topley $\mathrm{N}$, et al. Peritoneal macrophage heterogeneity is associated with different peritoneal dialysis outcomes. Kidney Int. (2017) 91:1088-103. doi: 10.1016/j.kint.2016.10.030

18. Serbina N V, Pamer EG. Monocyte emigration from bone marrow during bacterial infection requires signals mediated by chemokine receptor CCR2. Nat Immunol. (2006) 7:311-7. doi: 10.1038/ni1309

19. Auffray C, Fogg D, Garfa M, Elain G, Join-Lambert O, Kayal S, et al. Monitoring of blood vessels and tissues by a population of monocytes with patrolling behavior. Science. (2007) 317:666-70. doi: 10.1126/science.1142883

20. Merad M, Sathe P, Helft J, Miller J, Mortha A. The dendritic cell lineage: ontogeny and function of dendritic cells and their subsets in the steady state and the inflamed setting. Annu Rev Immunol. (2013) 31:563-604. doi: 10.1146/annurev-immunol-020711-074950

21. Guilliams M, Ginhoux F, Jakubzick C, Naik SH, Onai N, Schraml BU, et al. Dendritic cells, monocytes and macrophages: a unified nomenclature based on ontogeny. Nat Rev Immunol. (2014) 14:571-8. doi: 10.1038/nri3712

22. Haniffa M, Collin M, Ginhoux F. Ontogeny and functional specialization of dendritic cells in human and mouse. Adv Immunol. (2013) 120:1-49. doi: 10.1016/B978-0-12-417028-5.00001-6

23. Imai T, Kato Y, Kajiwara C, Mizukami S, Ishige I, Ichiyanagi T, et al. Heat shock protein 90 (HSP90) contributes to cytosolic translocation of extracellular antigen for cross-presentation by dendritic cells. Proc Natl Acad Sci USA. (2011) 108:16363-8. doi: 10.1073/pnas.1108372108

24. Schlitzer A, McGovern N, Teo P, Zelante T, Atarashi K, Low D, et al. IRF4 Transcription factor-dependent $\mathrm{CD} 11 \mathrm{~b}^{+}$dendritic cells in human and mouse control mucosal IL-17 cytokine responses. Immunity. (2013) 38:970-83. doi: 10.1016/j.immuni.2013.04.011

25. Yeo C, Saunders N, Locca D, Flett A, Preston M, Brookman P, et al. FicollPaque $^{\mathrm{TM}}$ versus lymphoprep ${ }^{\mathrm{tm}}$ : a comparative study of two density gradient media for therapeutic bone marrow mononuclear cell preparations. Regen Med. (2009) 4:689-96. doi: 10.2217/rme.09.44

26. Patel AA, Zhang Y, Fullerton JN, Boelen L, Rongvaux A, Maini AA, et al. The fate and lifespan of human monocyte subsets in steady state and systemic inflammation. J Exp Med. (2017) 214:1913-23. doi: 10.1084/jem.201 70355

27. Ohradanova-Repic A, Machacek C, Fischer MB, Stockinger H. Differentiation of human monocytes and derived subsets of macrophages and dendritic cells by the HLDA10 monoclonal antibody panel. Clin Transl Immunol. (2016) 5:e55. doi: 10.1038/cti.2015.39

28. Andersson LIM, Cirkic E, Hellman P, Eriksson H. Myeloid blood dendritic cells and monocyte-derived dendritic cells differ in their endocytosing capability. Hum Immunol. (2012) 73:1073-81. doi: 10.1016/j.humimm.2012.08.002

29. Dinter J, Gourdain P, Lai NY, Duong E, Bracho-Sanchez E, Rucevic M, et al. Different antigen-processing activities in dendritic cells, macrophages, and monocytes lead to uneven production of HIV epitopes and affect CTL recognition. J Immunol. (2014) 193:4322-34. doi: 10.4049/jimmunol. 1400491

30. Foote JR, Levine AP, Behe P, Duchen MR, Segal AW. Imaging the neutrophil phagosome and cytoplasm using a ratiometric $\mathrm{pH}$ indicator. J Vis Exp. (2017) 122:55107. doi: 10.3791/55107

31. Schneider CA, Rasband WS, Eliceiri KW. NIH Image to ImageJ: 25 years of image analysis. Nat Methods. (2012) 9:671-5. doi: 10.1038/nmeth.2089

32. Morgan D, Capasso M, Musset B, Cherny VV, Ríos E, Dyer MJ, et al. Voltage-gated proton channels maintain $\mathrm{pH}$ in human neutrophils during phagocytosis. Proc Natl Acad Sci USA. (2009) 106:18022-7. doi: 10.1073/pnas.0905565106

33. Maini A, Foote JR, Hayhoe R, Patel AA, O’Brien A, Avraham-Davidi I, et al. Monocyte and neutrophil isolation, migration, and phagocytosis assays. Curr Protoc Immunol. (2018) 122:e53. doi: 10.1002/cpim.53

34. Rydstrom A, Wick MJ. Monocyte recruitment, activation, and function in the gut-associated lymphoid tissue during oral salmonella infection. J Immunol. (2007) 178:5789-801. doi: 10.4049/jimmunol.178.9.5789

35. Jankowski A, Grinstein S. Modulation of the cytosolic and phagosomal $\mathrm{pH}$ by the NADPH oxidase. Antioxid Redox Signal. (2002) 4:61-8. doi: $10.1089 / 152308602753625861$

36. Cross AR, Jones OT. The effect of the inhibitor diphenylene iodonium on the superoxide-generating system of neutrophils. Specific labelling of a component polypeptide of the oxidase. Biochem J. (1986) 237:111-6. doi: $10.1042 /$ bj2370111

37. De Rossi L, Gott K, Horn N, Hecker K, Hutschenreuter G, Rossaint R. Xenon preserves neutrophil and monocyte function in human whole blood. Can $J$ Anesth. (2002) 49:942-5. doi: 10.1007/BF03016879

38. Chu J, Song HH, Zarember KA, Mills TA, Gallin JI. Persistence of the bacterial pathogen Granulibacter bethesdensis in chronic granulomatous disease monocytes and macrophages lacking a functional NADPH oxidase. J Immunol. (2013) 191:3297-307. doi: 10.4049/jimmunol. 1300200 
39. See P, Dutertre CA, Chen J, Günther P, McGovern N, Irac SE, et al. Mapping the human DC lineage through the integration of highdimensional techniques. Science. (2017) 356:eaag3009. doi: 10.1126/science. aag3009

40. Villani AC, Satija R, Reynolds G, Sarkizova S, Shekhar K, Fletcher J, et al. Single-cell RNA-seq reveals new types of human blood dendritic cells, monocytes, and progenitors. Science. (2017) 356:eaah4573. doi: $10.1126 /$ science.aah4573

41. Goudot C, Coillard A, Villani AC, Gueguen P, Cros A, Sarkizova $S$, et al. Aryl hydrocarbon receptor controls monocyte differentiation into dendritic cells versus macrophages. Immunity. (2017) 47:582-96.e6. doi: 10.1016/j.immuni.2017.08.016

42. Lee J, Breton G, Oliveira TY, Zhou YJ, Aljoufi A, Puhr S, et al. Restricted dendritic cell and monocyte progenitors in human cord blood and bone marrow. J Exp Med. (2015) 212:385-99. doi: 10.1084/jem.20141442

43. Breton G, Lee J, Zhou YJ, Schreiber JJ, Keler T, Puhr S, et al. Circulating precursors of human $\mathrm{CD}_{1} \mathrm{c}^{+}$and $\mathrm{CD} 141^{+}$dendritic cells. J Exp Med. (2015) 212:401-13. doi: 10.1084/jem.20141441

44. Robbins SH, Walzer T, Dembélé D, Thibault C, Defays A, Bessou G, et al. Novel insights into the relationships between dendritic cell subsets in human and mouse revealed by genome-wide expression profiling. Genome Biol. (2008) 9:R17. doi: 10.1186/gb-2008-9-1-r17

45. Nastasi C, Candela M, Bonefeld CM, Geisler C, Hansen M, Krejsgaard T, et al. The effect of short-chain fatty acids on human monocyte-derived dendritic cells. Sci Rep. (2015) 5:16148. doi: 10.1038/srep16148

46. Dingjan I, Verboogen DR, Paardekooper LM, Revelo NH, Sittig SP, Visser LJ, et al. Lipid peroxidation causes endosomal antigen release for crosspresentation. Sci Rep. (2016) 6:22064. doi: 10.1038/srep22064

47. Kourjian G, Rucevic M, Berberich MJ, Dinter J, Wambua D, Boucau J, et al. HIV protease inhibitor-induced cathepsin modulation alters antigen processing and cross-presentation. J Immunol. (2016) 196:3595-607. doi: 10.4049/jimmunol.1600055

48. Resnitzky P, Shaft D, Yaari A, Nir E. Distinct intracellular lysozyme content in normal granulocytes and monocytes: a quantitative immunoperoxidase and ultrastructural immunogold study. J Histochem Cytochem. (1994) 42:1471-7. doi: $10.1177 / 42.11 .7930529$

49. Lewis CE, Mccarthy SP, Lorenzen J, Mcgee Nuffield D. Differential effects of LPS, IFN-y and TNFa on the secretion of lysozyme by individual human mononuclear phagocytes: relationship to cell maturity. Immunology. (1990) 69:402-8.

50. Senior RM, Campbell EJ. Cathepsin G in human mononuclear phagocytes: comparisons between monocytes and U937 monocyte-like cells. J Immunol. (1984) 132:2547-51.
51. Wardlaw AC. The complement-dependent bacteriolytic activity of normal human serum. I. The effect of $\mathrm{pH}$ and ionic strength and the role of lysozyme. J Exp Med. (1962) 115:1231-49. doi: 10.1084/jem.115.6.1231

52. Liu X, Lu L, Yang Z, Palaniyandi S, Zeng R, Gao LY, et al. The neonatal FcR-mediated presentation of immune-complexed antigen is associated with endosomal and phagosomal $\mathrm{pH}$ and antigen stability in macrophages and dendritic cells. J Immunol. (2011) 186:4674-86. doi: 10.4049/jimmunol.1003584

53. Segura E, Durand M, Amigorena S. Similar antigen cross-presentation capacity and phagocytic functions in all freshly isolated human lymphoid organ-resident dendritic cells. J Exp Med. (2013) 210:1035-47. doi: 10.1084/jem.20121103

54. Salao K, Jiang L, Li H, Tsai VW, Husaini Y, Curmi PM, et al. CLIC1 regulates dendritic cell antigen processing and presentation by modulating phagosome acidification and proteolysis. Biol Open. (2016) 5:620-30. doi: 10.1242/bio.018119

55. Thiele L, Merkle HP, Walter E. Phagocytosis and phagosomal fate of surfacemodified microparticles in dendritic cells and macrophages. Pharm Res. (2003) 20:221-8. doi: 10.1023/A:1022271020390

56. Savina A, Jancic C, Hugues S, Guermonprez P, Vargas P, Moura IC, et al. NOX2 controls phagosomal ph to regulate antigen processing during crosspresentation by dendritic cells. Cell. (2006) 126:205-18. doi: 10.1016/j.cell.2006.05.035

57. Sturgill-Koszycki S, Schlesinger PH, Chakraborty P, Haddix PL, Collins HL, Fok AK, et al. Lack of acidification in mycobacterium phagosomes produced by exclusion of the vesicular proton-ATPase. Science. (1994) 263:678-81. doi: $10.1126 /$ science. 8303277

58. Podinovskaia M, Lee W, Caldwell S, Russell DG. Infection of macrophages with Mycobacterium tuberculosis induces global modifications to phagosomal function. Cell Microbiol. (2013) 15:843-59. doi: 10.1111/cmi. 12092

Conflict of Interest Statement: The authors declare that the research was conducted in the absence of any commercial or financial relationships that could be construed as a potential conflict of interest.

Copyright (c) 2019 Foote, Patel, Yona and Segal. This is an open-access article distributed under the terms of the Creative Commons Attribution License (CC BY).

The use, distribution or reproduction in other forums is permitted, provided the original author(s) and the copyright owner(s) are credited and that the original publication in this journal is cited, in accordance with accepted academic practice. No use, distribution or reproduction is permitted which does not comply with these terms. 